\title{
ANALISIS KANDUNGAN FORMALIN PADA MIE BASAH PADA BEBERAPA LOKASI DI KOTA AMBON
}

\section{ANALYSIS OF FORMALDEHYDE CONTENT IN WET NOODLES FROM SEVERAL SPOT IN AMBON CITY}

\author{
Yusthinus T. Male, Lina I. Letsoin dan Netty A. Siahaya \\ Jurusan Kimia, Fakultas Matematika dan IImu Pengetahuan Alam, Universitas Pattimura \\ Jl. Ir. M. Putuhena, Kampus Poka Ambon 97233 \\ E-mail : yusmale@fmipa.unpatti.ac.id
}

Received : 08/12/2017; revised : 19/12/2017; accepted : 28/12/2017

Published online : 29/12/2017

\begin{abstract}
ABSTRAK
Telah dilakukan penelitian untuk menganalisis kandungan formalin mie basah pada beberapa lokasi di Kota Ambon. Tujuan dari penelitian ini adalah untuk menentukan kandungan formalin pada mie basah. Penelitian ini menggunakan tiga tahap pengujian. Pada tahap awal, dilakukan uji fisik dan analisis kualitatif untuk menentukan ada tidaknya formalin dan analisis kuantitatif digunakan untuk menentukan kadar formalin dalam mie basah. Dari pengamatan uji fisik, ditemukan dua dari empat belas sampel mie basah mengandung formalin yaitu sampel $J$ (Batu Merah) dan $K$ (Mardika) karena tetap awet sampai tiga hari. Analisis kualitatif dengan pereaksi asam kromatofat tidak menunjukkan perubahan warna yang khas. Pada pengamatan uji fisik mie basah dua sampel yang mengandung formalin dilanjutkan dengan analisis kuantitatif menggunakan Spektrofotometri UV-Vis pada panjang gelombang $520 \mathrm{~nm}$. Kadar formalin untuk sampel $\mathrm{J}$ (Batu Merah) sebesar 9,07 mg/kg dan sampel K (Mardika) sebesar 10,01 mg/kg. Sesuai syarat mutu mie basah pada SNI 01-2987-1992, mie basah tidak boleh mengandung formalin.
\end{abstract}

Kata kunci: Formalin, mie basah, uji fisik, spektrofotometri UV-Vis, SNI 01-2987-1992

\begin{abstract}
A research to analyze the formaldehyde content in wet noodles from several spot in Ambon cityhas been done. The Aim of this research is to determine the content of formaldehyde in wet noodles. This research uses three stepstesting method. The First stept is physical tests and qualitative analysis which will be used to determine the content formaldehyde followed by quantitative analysis to determine formaldehyde content in wet noodles. The results of the of physical tests showingthat two of fourteen samples containing formaldehyde, that isJ (Batu Merah) and K (Mardika) samples because of durability up to three days. Qualitative analysis using chromatophate acid reagent showing no observable in color changes. For observationin physical test, the resultsshowing that two samples containing formaldehyde based on analysis using UV-Vis Spectrophotometry. Formaldehyde levels for J (Batu Merah) samples were 9.07 ppm and K (Mardika) samples were 10.01 ppm. According to SNI 01-2987-1992 (Indonesian standard, for Wet Noodle), formaldehyde is not allowed in wet noodles.
\end{abstract}

Keywords: Formaldehyde, wet noodles, physical test, UV-Vis spectrophotometry, SNI 01-2987-1992

\section{PENDAHULUAN}

Indonesia adalah negara berkembang yang berlimpah dengan sumber daya hayati khususnya bahan pangan. Makanan merupakan bagian penting dari kehidupan manusia yang sebagian besar dipengaruhi oleh faktor lingkungan yang erat kaitannya dengan kesehatan. Pangan yang murah dan praktis belum tentu aman bagi konsumen khususnya makanan olahan yang sering ditemukan di tempat-tempat umum sehingga sangat berpotensi terkontaminasi oleh cemaran fisik, mikrobiologi dan bahan-bahan kimia berbahaya. Makanan yang terkontaminasi jika dikonsumsi akan berdampak buruk baik dari aspek kesehatan, gizi, dan keamanan pangan (Cahyadi 2008).

Salah satu bahan kimia berbahaya yang sering digunakan dalam pengawetan bahan pangan olahan adalah formalin. Dewasa ini, banyak kita temui makanan olahan di masyarakat, seperti mie, bakso, bubur, pudding, nugget, susu, kornet, ikan, dan lain-lain. Patut kita cermati di sini, makanan tersebut, pasti membutuhkan bahan pengawet, karena untuk 
memproduksi produk-produk makanan tersebut dalam jumlah yang besar, tak mungkin jika tidak menggunakan bahan pengawet. Sebuah produk berpotensi bebas dari bahan pengawet, jika daya simpannya relatif singkat, yaitu berkisar antara tiga sampai empat hari. Memprihatinkan, pada beberapa bahan makanan masih ditemukan formalin yang digunakan sebagai pengawet.

Formalin merupakan larutan yang dibuat dari $37 \%$ formaldehida $(\mathrm{HCOH})$ dalam air. Formalin sangat berbahaya bagi kesehatan, karena bersifat karsinogen (menyebabkan kanker), mutagen (menyebabkan perubahan sel dan jaringan tubuh) serta sangat korosif dan iritatif. Formalin biasanya digunakan sebagai desinfektan, pembasmi serangga, bahan pengawet mayat dan berbagai jenis bahan industri non makanan. Penggunaan formalin dalam makanan sangat membahayakan konsumen. Tetapi masih ditemukan pengolah makanan yang menambahkan formalin sebagai pengawet makanan (Yuliarti 2007).

Mie basah merupakan makanan berbahan dasar tepung dan banyak dikonsumsi oleh masyarakat karena pengolahannya relatif mudah. Akses yang mudah serta banyaknya penggemar mie mendorong penggunaan bahan kimia seperti formalin. Ciri-ciri mie basah yang mengandung formalin yakni tampak mengkilat, tidak mudah putus atau tidak lengket, selain aroma terigu biasanya tercium aroma seperti obat, dan daya awet bisa dua hari atau lebih. Penggunaan formalin dalam makanan dapat menyebabkan masalah kesehatan yakni gangguan pernapasan, sakit kepala dan kanker paru-paru (Cahyadi 2008).

Data penelitian pada tahun 2004 oleh BPOM di Indonesia menemukan bahwa terdapat kandungan bahan kimia formalin paling banyak pada mie basah. Hasil penelitian Shenna (2011) pada sepuluh sampel mie basah menunjukkan bahwa tujuh sampel mie basah di Bogor, Jakarta dan Depok mengandung formalin. Hal yang sama juga dikemukakan oleh Habsah (2012), yaitu dari 20 sampel mie basah di Depok, ditemukan 11 sampel positif mengandung formalin. Sedangkan hasil penelitian oleh Ekki (2013) yang dilakukan terhadap 36 pedagang mie basah di Pasar Tradisional Kota Semarang menunjukkan bahwa $41,7 \%$ mie basah mengandung formalin dengan kadar rata-rata 795,71 ppm.

Penelitian ini dilakukan untuk mengetahui tingkat penggunaan formalin pada mie basah di Kota Ambon. Perkembangan pariwisata mendorong tumbuhnya restoran dan pusat jajanan di Kota Ambon sehingga diperlukan penelitian awal untuk mengetahui penggunaan bahan-bahan kimia berbahaya pada bahan makanan.

\section{METODE PENELITIAN}

\section{Alat dan Bahan}

Alat-alat yang digunakan dalam penelitian ini adalah seperangkat alat gelas dan Spektrofotometri UV-Vis (Shimadzu UV-1201). Bahan-bahan yang digunakan dalam penelitian ini adalah sampel mie basah, asam kromatofat, formaldehid 37\%, natrium sulfat, natrium hidroksida, merkuri oksida, asam klorida, indikator metil merah dan petroleum eter.

\section{Keadaan Umum Lokasi Pengambilan Sampel}

Sampel mie basah diambil pada tempat penjualan bakso yang cukup banyak memiliki konsumen dan berkedudukan tetap (memiliki tempat berjualan tetap/ tidak berpindah lokasi). Sampling dilakukan pada empat belas lokasi di Kota Ambon dan sekitarnya. Nama lokasi dan kode sampel disajikan pada Tabel 1 dan peta sampling diperlihatkan pada Gambar 1.

Tabel 1. Kode Sampel, Lokasi, dan Titik-Titik Koordinat

\begin{tabular}{clc}
\hline No & Lokasi & Kode Sampel \\
\hline 1 & Wayame & $\mathrm{A}$ \\
2 & Pasar Rumah Tiga & $\mathrm{B}$ \\
3 & Waiheru & $\mathrm{C}$ \\
4 & Natsepa & $\mathrm{D}$ \\
5 & Passo & $\mathrm{E}$ \\
6 & Lateri & $\mathrm{F}$ \\
7 & Latta & $\mathrm{G}$ \\
8 & Galala & $\mathrm{H}$ \\
9 & Kebun Cengkeh & $\mathrm{I}$ \\
10 & Batu Merah & $\mathrm{J}$ \\
11 & Mardika & $\mathrm{K}$ \\
12 & Samping Amplaz & $\mathrm{L}$ \\
13 & Air Mata Cina & $\mathrm{M}$ \\
14 & Jalan Baru & $\mathrm{N}$ \\
15 & Warung Mie Damai & Kontrol \\
\hline
\end{tabular}




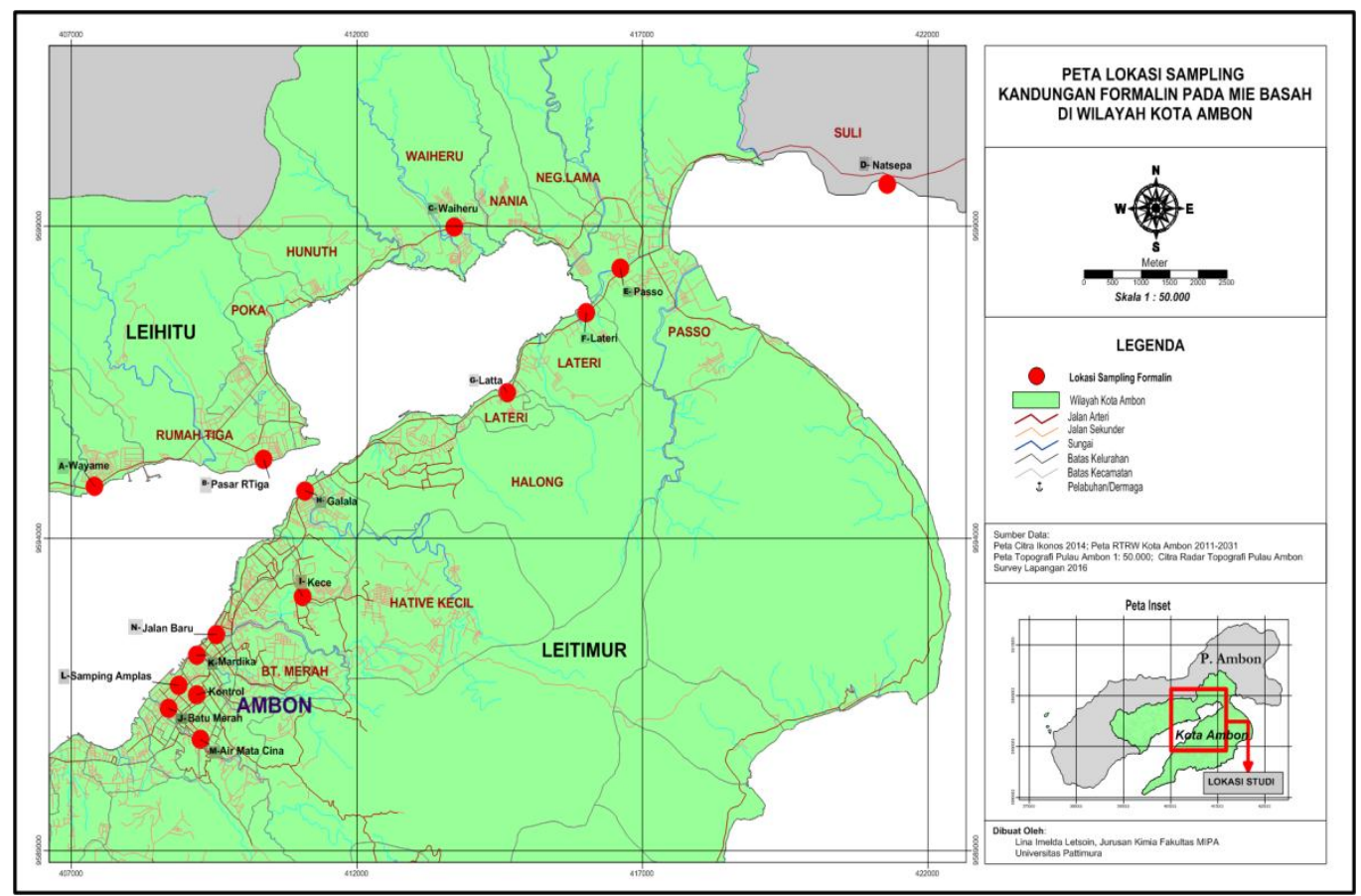

Gambar 1. Titik-titik lokasi pengambilan sampel

\section{Pengamatan Uji Fisik Mie Basah}

Disiapkan mie kontrol yaitu mie yang dianggap bebas formalin sebagai pembanding atau sebagai kontrol dan sampel uji. Sampel diletakkan pada wadah yang kering dan disimpan pada suhu ruang. Mie basah diamati secara visual dan dilakukan penilaian dalam satu hari sampai dua hari secara subjektif yang meliputi aroma, tekstur, dan masa simpan. Penilaian dihentikan jika telah terjadi perubahan aroma dan tekstur.

\section{Analisis Kualitatif Formalin}

Sampel yang telah dihaluskan ditimbang sebanyak $10 \mathrm{~g}$ dimasukkan ke dalam gelas kimia dan ditambahkan $100 \mathrm{~mL}$ aquabidest. Ke dalam tabung reaksi dimasukkan $5 \mathrm{~mL}$ filtrat dan $5 \mathrm{~mL}$ asam kromatofat $0,5 \%$ dalam asam sulfat $60 \%$. Larutan dipanaskan selama 15 menit pada suhu $100^{\circ} \mathrm{C}$. Jika mengandung formalin larutan akan berwarna merah keunguan (Cahyadi, 2008).

\section{Analisis Kuantitatif Formalin}

Larutan standar dibuat dengan mengencerkan larutan induk formaldehid 37\% (formalin) konsentrasi $0 ; 1,0 ; 1,5 ; 2,0 ; 2,5$, dan $3,0 \mathrm{ppm}$. Masing-masing $5 \mathrm{~mL}$ larutan dimasukkan ke dalam tabung reaksi, ditambahkan $5 \mathrm{~mL}$ asam kromatofat $0,5 \%$ dalam asam sulfat $60 \%$. Larutan dipanaskan selama 15 menit pada suhu $100^{\circ} \mathrm{C}$ dan diukur serapannya menggunakan Spektrofotometri UV-Vis pada panjang gelombang $520 \mathrm{~nm}$, kemudian dibuat kurva kosentrasi larutan standar vs absorbansinya.

Sampel yang telah dihaluskan ditimbang sebanyak $10 \mathrm{~g}$ kemudian dimasukkan ke dalam gelas kimia dan ditambahkan $100 \mathrm{~mL}$ aquabidest. Ke dalam tabung reaksi dimasukkan $5 \mathrm{~mL}$ filtrat dan $5 \mathrm{~mL}$ asam kromatofat $0,5 \%$ dalam asam sulfat $60 \%$. Selanjutnya dipanaskan selama 15 menit pada suhu $100^{\circ} \mathrm{C}$ dan diukur serapannya menggunakan Spektrofotometri UVVis pada panjang gelombang $520 \mathrm{~nm}$ (Day dan Underwood, 1986).

\section{HASIL PENELITIAN DAN PEMBAHASAN}

\section{Pengamatan Uji Fisik Mie Basah}

Uji pengamatan mie basah secara visual dilakukan dengan cara mengamati dan mencatat perubahan dari parameter yang dijadikan acuan yaitu aroma, tekstur, dan daya awet. Pada penelitian ini, peneliti menggunakan sampel mie basah kontrol dibeli dari salah satu produsen mie basah di Kota Ambon yang dianggap tidak menggunakan formalin. Mie basah kontrol dalam penelitian ini memiliki tekstur tidak berminyak dan sebelum penyimpanan terasa agak lengket, setelah penyimpanan satu hari terjadi perubahan yaitu berbau tengik (basi) dan mulai berjamur. Hasil pengamatan ini sesuai dengan penelitian Eka (2013), bahwa mie basah (bebas formalin) mempunyai ciri-ciri fisik yaitu tidak berminyak, teksturnya lengket, tidak dapat disimpan lama, dan mudah berjamur. Hasil pengamatan ciri fisik mie basah kontrol disajikan pada Gambar 2. 
Hari ke-1

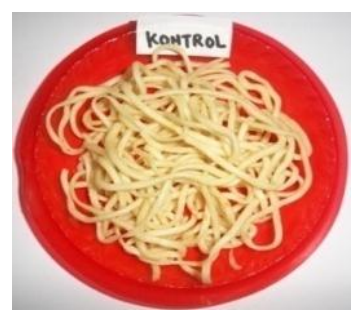

Hari ke-2

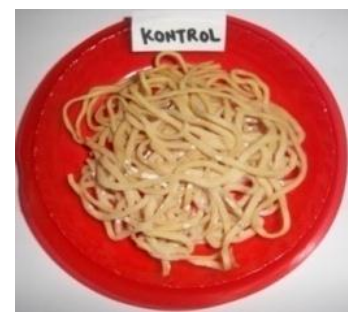

Gambar 2. Mie basah kontrol sebelum penyimpanan setelah penyimpanan satu hari

Dari empat belas sampel mie basah yang diteliti, pada hari ketiga, dua belas sampel mengalami perubahan tekstur, yaitu terasa lengket, berbau tengik, warna agak pudar dan mulai berjamur ; Sedangkan dua sampel (sampel $\boldsymbol{J}$ dan sampel $\boldsymbol{K}$ ) diduga mengandung formalin

Hari ke-1

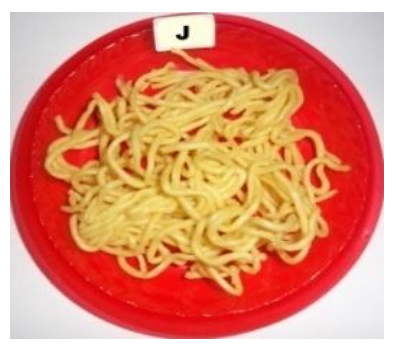

Hari ke -1

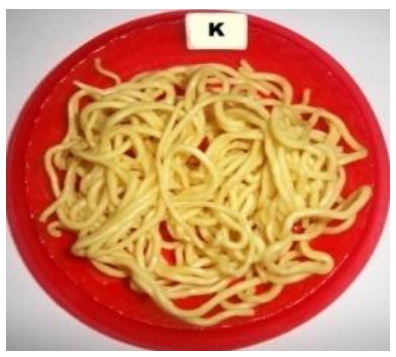

karena tidak mengalami perubahan warna, aroma dan tekstur. Gambar sampel $\boldsymbol{J}$ dan $\boldsymbol{K}$ yang diduga mengandung formalin disajikan pada Gambar 3.

Gambar 3. Hasil uji pengamatan sampel $\boldsymbol{J}$ dan $\boldsymbol{K}$ yang diduga mengandung formalin

\section{Analisis Kualitatif Formalin}

Analisis

menggunakan metode pereaksi asam

kromatofat. Asam kromatofat digunakan untuk mengikat formalin agar terlepas dari bahan. Formalin juga bereaksi dengan asam kromatofat menghasilkan senyawa kompleks yang berwarna merah keunguan. Reaksinya dapat dipercepat dengan cara menambahkan asam fosfat dan hidrogen peroksida. Larutan blanko yang mengandung formalin mengalami perubahan warna menjadi merah keunguan (kontrol positif). Perubahan warna juga terjadi pada sampel $\boldsymbol{J}$ dan $\boldsymbol{K}$ walaupun intensitas warnanya sangat lemah sehingga menyulitkan pengamatan secara visual. Hasil uji kualitatif disajikan pada Gambar 4. 


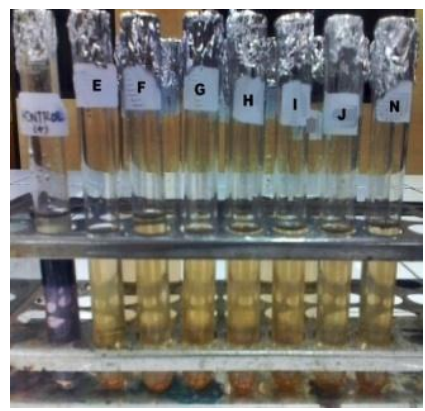

Gambar 4. Uji kualitatif formalin dalam mie basah

\section{Analisis Kuantitatif Kandungan Formalin}

Untuk memperkuat asumsi keberadaan formalin pada Sampel $\boldsymbol{J}$ dan $\boldsymbol{K}$ melalui pembuktian awal dengan uji fisik dan analisis kualitatif, dilakukan analisis kuantitatif. Analisis kurva kalibrasi dan absorbansi larutan sampel membuktikan bahwa kedua sampel mengandung formalin. Data pengukuran absorbansi dan kadar formalin pada sampel $\boldsymbol{J}$ (Batu Merah) dan $\boldsymbol{K}$ (Mardika) disajikan pada Tabel 2.

Tabel 2. Data Pengukuran Absorbansi dan Kadar Formalin

\begin{tabular}{ccccc}
\hline Kode sampel & $\begin{array}{c}\text { Berat sampel } \\
(\mathbf{g})\end{array}$ & Absorbansi & $\begin{array}{c}\text { Kadar } \\
(\mathbf{m g} / \mathbf{L})\end{array}$ & $\begin{array}{c}\text { Formalin } \\
(\mathbf{m g} / \mathbf{k g})\end{array}$ \\
\hline $\mathrm{J}$ & 10,1240 & 0,050 & 0,9183 & 9,07 \\
$\mathrm{~K}$ & 10,1928 & 0,055 & 1,0204 & 10,01 \\
\hline
\end{tabular}

Hasil analisis kadar formalin dalam mie basah pada penelitian ini lebih tinggi jika dibandingkan dengan hasil penelitian oleh Silvana (2016) di sekitar Universitas Tarumanegara Jakarta bahwa kadar formalin sebesar $5,99 \mathrm{mg} / \mathrm{kg}$. Jika dibandingkan dengan hasil penelitian oleh Aqnes dkk (2009) di Pasar Johar Semarang kadar formalin dalam mie basah sebesar 271,749 $\mathrm{mg} / \mathrm{kg}$. Menurut SNI 01-2987-1992, syarat mutu mie basah harus tidak mengandung formalin. Dengan demikian dua sampel ( $\mathrm{J}$ dan $\mathrm{K}$ ) pada penelitian ini tidak layak dikonsumsi.

\section{KESIMPULAN}

Berdasarkan hasil penelitian diperoleh bahwa Hasil analisis keberadaan kandungan formalin pada empat belas sampel mie basah di Kota Ambon, ditemukan dua sampel mengandung formalin yaitu sampel $\boldsymbol{J}$ (Batu Merah), sebesar $9,07 \mathrm{mg} / \mathrm{kg}$ dan sampel $\boldsymbol{K}$ (Mardika) sebesar $10,01 \mathrm{mg} / \mathrm{kg}$. Berdasarkan syarat mutu SNI 01-2987-1992, tidak diperbolehkan adanya formalin dalam mie basah, penelitian ini mengindikasikan adanya mie basah yang mengandung formalin di Kota Ambon.

\section{DAFTAR PUSTAKA}

Aqnes B., Supriyanti, Musinah S. 2009. Pengaruh perendaman dalam air hangat terhadap kandungan formalin pada mie basah dari tiga produsen yang dijual $\mathrm{Di}$ Pasar Johar Semarang. Jurnal IImu Farmasi dan Farmasi Klinik 6(1) : 1-6.

Cahyadi, W. 2008. Analisis dan aspek kesehatan bahan tambahan pangan Edisi 2 Cetakan I. Jakarta : Bumi Aksara.

Day, R.A. Jr. and Underwood, A.L. 1986. Analisis kimia kuantitatif, diterjemahkan Soendoro, $R$. Erlangga : Jakarta

Eka, R. 2013. Rahasia Mengetahui Makanan Berbahaya. Titik Media Publisher : Jakarta

Ekki, I. R.U. 2013. Studi identifikasi kandungan formalin dan boraks dalam mie basah yang diperoleh dari Pasar Tradisional Kota Semarang. Skripsi. Fakultas Kesehatan Diponegoro. Semarang.

Habsah. 2012. Gambaran pengetahuan pedagang mie basah terhadap perilaku penambahan boraks dan formalin pada mie basah di kantin-kantin Universitas X Depok Tahun 2012. Skripsi. Program Studi IImu Gizi. Fakultas Kesehatan Masyarakat. Depok.

Singgih, H. 2013. Uji Kandungan formalin pada ikan asin menggunakan sensor warna 
dengan bantuan FMR. Jurnal ELTEK 11 (1).

Silvana, P. T. 2016. Uji Formalin pada mie basah di sekitar Universitas Tarumagara Jakarta. Dalam : Prosiding Seminar Hasil Penerapan Penelitian dan Pengambdian Masyarakat III 2016. P-ISSN:2356-3176, E-ISSN: 2527-5658

Shenna, A. 2011. Kadar formalin dan metanil yellow dalam mie basah yang beredar di pasaran secara kromatografi cair kinerja tinggi. Skripsi. Program Studi Kimia. Fakultas Matematika dan IImu Pengetahuan Alam Universitas Pakuan. Bogor.

Widyaningsih, T.D. dan Murtini, E. S. 2006. Alternatif pengganti formalin pada produk pangan. Trubus Agrisarana : Jakarta.

Yuliarti N. 2007. Awasi bahaya dibalik lezatnya makanan. Penerbit Andi Offset : Yogyakarta. 